\title{
COMMENTARY
}

\section{Do earplugs stop noise from driving critical care patients into delirium?}

\author{
Gary H Mills',2 and Richard S Bourne*3 \\ See related research by Van Rompaey et al., http://ccforum.com/content/16/3/R73
}

\begin{abstract}
Quality sleep is a problem for the critically ill who are cared for in an environment where interventions night and day are common, staff members are constantly present in relatively high numbers, and treatment is accompanied by a range of changing warning tones and alarms and lights. These critical care units are generally designed without a focus on patient comfort, sleep, and rest and often lack access to appropriate natural daylight. To add to this problem, critical illness, particularly sepsis, disrupts circadian rhythms and sleep patterns, and disruption of circadian rhythms, in turn, impairs immunity and contributes to delirium. In a randomized controlled trial in the previous issue of Critical Care, Van Rompaey and colleagues have intervened to reduce noise, which is a key factor in this disruption, by having patients use earplugs at night. Delirium was assessed by using the NEECHAM (Neelon and Champagne) confusion scale, and sleep perception was assessed by patients' responses to a set of five questions. After the first night, patients reported a better sleep perception and the occurrence of delirium was reduced (hazard ratio of 0.47 for the development of delirium) or was delayed. The study did not quantify adequacy of pain control in postsurgical patients and used patient reporting to assess sleep. Whether patients were receiving respiratory or other organ support was not reported. The potential benefit of earplugs is an important practical finding that could be implemented in most intensive care units.
\end{abstract}

\section{Introduction}

Lack of quality sleep is a major problem for all patients, especially those who are critically ill, and so ways of avoiding disruption by sudden or even sustained noise may well have a role in the modern critical care unit. In the previous issue of Critical Care, Van Rompaey and colleagues [1] argue that earplug use not only produces better reported sleep but also decreases delirium.

\section{Does patient use of earplugs reduce delirium?}

Reduced sleep quantity and quality have significant implications for critically ill patients [2] and are made worse by environmental factors, including patient care activities, noise, and light interruptions [3]. Mean levels of peak noise are comparable to those of a busy office and account for $15 \%$ to $20 \%$ of patient arousals or awakenings [4]. Other factors such as medication exposure and the acute illness itself are also important; for example, endotoxin disrupts sleep patterns in animal models [5] and in patients with sepsis [6]. To make matters worse, sleep deprivation itself may impair immune function by reducing natural killer and cellular immune responses in humans [7], promoting bacterial invasion [8], and reducing the response to immunization [9].

Increasing severity and number of organ dysfunctions indicate a worsening prognosis for patients. Delirium may well indicate organ dysfunction of the brain and is often an early indicator of a more general deterioration. Patients who develop delirium have increased critical care and hospital length of stay, mortality, and longerterm cognitive impairment [10]. Development of hyperactive delirium complicates critical care therapy, causing, for example, intolerance of continuous positive airway pressure or non-invasive ventilation or increased doses of sedation or related medication to control behavior, which in turn accumulate. These may then increase somnolence and adverse effects and impair other body organ systems. Hypoactive delirium may not be identified or may be misdiagnosed, leading to delays in correction of delirium risk factors and hence increasing delirium duration [10].

The environment of the intensive care unit is frequently ignored as a key factor in patient well-being. Staff
"Departments of Pharmacy and Critical Care, Sheffield Teaching Hospitals,

Full list of author information is available at the end of the article 
members may not recognize the significant disruption caused by care activities, noise at night, and disrupted day/night light patterns. For many years, architects or hospital planners have neglected appropriate sound insulation or the inclusion of sources of natural light to reinforce the day/night cycle. As a result for many critical care environments, it may be important to accept that, in some circumstances, environmental change will take years to effect and will be expensive. Therefore, simple and low-cost patient interventions, such as the use of earplugs, may be a pragmatic solution for many.

This study illustrates some of the difficulties of conducting this type of study on relatively large numbers of patients in critical care. It shows the importance of reducing ambient noise and reinforces the worldwide need for a consistent focus on critical care unit design and staff behavior. Questions remain unanswered or factors remain difficult to measure. Firstly, single-center studies, such as this one, present problems for determining the effectiveness of the application of any therapy to a less cooperative environment in the future. For example, patient acceptance of earplugs was $79 \%$, which is much higher than the $10 \%$ reported in another sleep study [11]. We know that many of the patients are surgical and have similar Therapeutic Intervention Scoring System and Sequential Organ Failure Assessment scores and Simplified Acute Physiology Score, but we do not know how the patient groups differed in terms of type or effectiveness of analgesia. Despite the similar scores, we know that 22\% (treatment) versus 26\% (control) were emergency surgical patients. Could this have impacted on differing modes of analgesia or incidence of sepsis or medicine exposure? We also see the variable impact of critical care design: only $60 \%$ were exposed to visible daylight (a potential problem for many similar interventions in critical care units). It is hard to determine whether these differences in light levels and patterns were important [12-14]. The assessment of sleep is also difficult in critically ill patients, particularly in delirium-positive patients [15], and an invalidated subjective score was used. Noise is only one of the many modifiable risk factors for delirium [10], and the fact that the most significant difference was in the patients with mild confusion may explain the reported benefits of improved sleep. Despite these issues, 136 patients were included and randomly assigned (with 46 refusals), suggesting that this therapy could be widely applied with an improvement in hazard ratio of 0.47 for delirium.

\section{Conclusions}

In normal life, no one would argue that ongoing loud conversations, combined with sudden and inappropriate changes in light level, extremes of temperature, or the sound of car alarms outside, were conducive to nocturnal sleep, even in healthy individuals. So why do we accept a similar situation for the critically ill? This is an important study showing that a simple intervention to combat noise may have an important role in delirium risk reduction.

Competing interests

The authors declare that they have no competing interests.

\section{Author details}

'Departments of Anaesthesia and Critical Care, Sheffield Teaching Hospitals, Northern General Hospital, Herries Road, Sheffield, S5 7AU, UK. ${ }^{2}$ University of Sheffield, Western Bank, Sheffield, S10 2TN, UK. 'Departments of Pharmacy and Critical Care, Sheffield Teaching Hospitals, Northern General Hospital, Herries Road, Sheffield, S5 7AU, UK.

Published: 17 July 2012

References

1. Van Rompaey B, Elseviers MM, Van Drom W, Fromont V, Jorens PG: The effect of earplugs during the night on the onset of delirium and sleep perception: a randomized controlled trial in intensive care patients. Crit Care 2012, 16:R73.

2. Weinhouse GL, Schwab RJ: Sleep in the critically ill patient. Sleep 2006, 29:707-716.

3. Freedman NS, Gazendam J, Levan L, Pack Al, Schwab RJ: Abnormal sleep/ wake cycles and the effect of environmental noise on sleep disruption in the intensive care unit. Am J Respir Crit Care Med 2001, 163:451-457.

4. Cabello B, Thille AW, Drouot X, Galia F, Mancebo J, d'Ortho MP, Brochard L: Sleep quality in mechanically ventilated patients: comparison of three ventilatory modes. Crit Care Med 2008, 36:1749-1755.

5. Okada K, Yano M, Doki Y, Azama T, Iwanaga H, Miki H, Nakayama M, Miyata H, Takiguchi S, Fujiwara Y, Yasuda T, Ishida N, Monden M: Injection of LPS causes transient suppression of biological clock genes in rats. J Surg Res 2008, 145:5-12.

6. Mundigler G, Delle-Karth G, Koreny M, Zehetgruber M, Steindl-Munda P, MarktI W, Ferti L, Siostrzonek P: Impaired circadian rhythm of melatonin secretion in sedated critically ill patients with severe sepsis. Crit Care Med 2002, 30:536-540.

7. Irwin M, McClintick J, Costlow C, Fortner M, White J, Gillin JC: Partial night sleep deprivation reduces natural killer and cellular immune responses in humans. FASEB J 1996, 10:643-653

8. Everson CA, Toth $L A$ : Systemic bacterial invasion induced by sleep deprivation. Am J Physiol Regul Integr Comp Physiol 2000, 278:R905-916.

9. Spiegel K, Sheridan JF, Van Cauter E: Effect of sleep deprivation on response to immunization. JAMA 2002, 288:1471-1472.

10. Girard TD, Pandharipande PP, Ely EW: Delirium in the intensive care unit. Crit Care 2008, 12 Suppl 3:\$3

11. Bourne RS, Mills GH, Minelli C: Melatonin therapy to improve nocturnal sleep in critically ill patients: encouraging results from a small randomised controlled trial. Crit Care 2008, 12:R52.

12. Boivin DB, Czeisler CA: Resetting of circadian melatonin and cortisol rhythms in humans by ordinary room light. Neuroreport 1998, 9:779-782.

13. Perras B, Meier M, Dodt C: Light and darkness fail to regulate melatonin release in critically ill humans. Intensive Care Med 2007, 33:1954-1958.

14. Verceles AC, Silhan L, Terrin M, Netzer G, Shanholtz C, Scharf SM: Circadian rhythm disruption in severe sepsis: the effect of ambient light on urinary 6-sulfatoxymelatonin secretion. Intensive Care Med 2012, 38:804-810.

15. Bourne RS, Minelli C, Mills GH, Kandler R: Clinical review: sleep measurement in critical care patients: research and clinical implications. Crit Care 2007, 11:226.

doi:10.1186/cc11397

Cite this article as: Mills GH, Bourne RS: Do earplugs stop noise from driving critical care patients into delirium? Critical Care 2012, 16:139. 